\title{
Dedifferentiated liposarcoma
}

\author{
INSERM
}

\section{Source}

INSERM. (1999). Orphanet: an online rare disease and orphan drug data base.

Dedifferentiated liposarcoma. ORPHA:99970

Dedifferentiated liposarcoma (DDLS) is a high-grade subtype of liposarcoma (LS; see this term) that progresses from well-differentiated liposarcoma (WDLS; see this term), and most often occurs in the retroperitoneum. It is defined as a region of nonlipogenic sarcoma associated with WDLS. . 